\title{
A Proposed Classification of Genetically Determined Mosaicism in Man
}

\author{
MARGARET J. COREY and JAMES R. MILLER \\ From the Department of Paediatrics, University of British Columbia, Vancouver, B.C., Canada
}

Terms are often used in medical literature without a true awareness of their original meaning and previous usage. Although the recent advances in human cytogenetics have focused attention on the phenomenon of mosaicism, in fact the term 'mosaic' was used in biology and human genetics long before human cytogenetics was a recognized discipline.

The term 'mosaic' was borrowed, originally as a purely descriptive term, from the realm of fine arts. The term in its original context leaves no room for confusion or ambiguity. It is defined as 'the process of producing pictures or patterns by cementing together small pieces of stone or glass, etc. of various colours; pictures or patterns thus produced; the constructive or decorative materials of these' (Oxford Shorter Dictionary). This clarity of its meaning seems to make it a particularly appropriate descriptive term for certain naturally occurring patterned organisms (pathological or normal) where living tissues show the clear-cut difference of a mosaic. When used outside the realm of the inanimate it should always be thought of as 'mosaic-like', and any definition or classification should encompass all such mosaic-like situations regardless of their origin or level of observation. Such situations are sufficiently rare to attract widespread interest. They have been extensively investigated in plants (see Cramer, 1954 and Neilson-Jones, 1937, for reviews). More recently general discussions of their occurrence in the animal kingdom (Hannah-Alava, 1960) and in mice (Russell, 1964) have been published. Recent discussions of the subject (Lancet, 1965; Bain and Scott, I965; Engel, 1965) have tended to ignore the diversity of origin of mosaics, and the purpose of the present communication is to propose a general classification of mosaicism in man.

Received December 3, 1965.

\section{Biological Mosaicism}

According to Wilson (1928), Roux was the firsto to use the term 'mosaic' in a biological context. In? his work Uber Mosaikarbeit und neuere Entwick-cs lungshypothesen (1892-1893) he states, 'The develop=-D ment of the frog gastrula and of the embryo formed $\overrightarrow{\mathbb{D}}$ from it is from the second cleavage division onward 3 a mosaic work, consisting of at least four vertically믐 independent developing pieces' (from Wilson, $\overrightarrow{0}$ 1928). The implication here is that all livingo multicellular organisms in which differentiation. occurs are mosaics. During development differenti-o ation consists of a programmed progressive mosaicism and all human beings are mosaics. Thiso form of mosaicism, recognized as an aspect of normal development, will not be discussed furthero and in view of its universality will not be considerect5 in our classification. However, it should be 3 acknowledged that there may be some difficulty in distinguishing between normal mosaicism and? anomalous or pathological conditions in which the mosaicism is at a cellular level and involves a singleo tissue.

Pathological mosaicism is basically a develop mental problem. Although of great interest too geneticists, it is not concerned with the classicak Mendelian concept of the transfer of hereditary? characteristics from generation to generation buts rather with the branch of genetics which deals with. the transfer and utilization of this hereditary, information from the undifferentiated single-celled zygote to the millions of specialized cells of the complete organism. In this context, therefore a mosaic will be defined as an organism which displayg abnormal genotypic or phenotypic variation from celt to cell within the same tissue or genotypic variation between tissues.

Environmental Factors. Mosaicism may occasione ally result from the action of non-genetic factors 
Variation in biochemical or other environmental factors may cause the same gene to be expressed differently under different circumstances or even in different parts of the body. This mosaicism may closely mimic the genetically determined form in some instances. An example of this would be the heterochromia iridum observed in Horner's syndrome (Robinson, Dikrainian, and Roseborough, 1965), which is similar to the mosaicism of eye colour found in the Waardenburg syndrome and other genetically-determined heterochromias.

An outline of the proposed classification of genetically determined mosaicism is presented in the Table. It should be pointed out that though some of the categories have not yet been described

\section{TABLE}

\section{A PROPOSED CLASSIFICATION OF GENETICALLY DETERMINED MOSAICISM IN MAN}

A MOSAIC is an organism which displays abnormal genotypic or phenotypic variation from cell to cell within the same tissue or genotypic variation between tissues.

A: Genetically uniform mosaics

(1) Caused by specific genes-pattern loci

(2) Caused by variation in gene expression

(a) Lyon inactive-X theory

(b) Variegated-type position effect

(c) Controlling elements

(3) Non-genetic inheritance-cytoplasmic structures

B: Chimeras-a CHIMERA is an organism that is not genetically

(1) Post-zygotic uniform throughout

(a) Involving cells derived from a single zygote

(i) somatic crossing-over

(ii) somatic mutation

(iii) somatic segregation and reduction

(iv) polyploidy

(b) Involving cells derived from different zygotes

(i) chorionic vascular anastomosis

(ii) maternal-foetal exchange

(iii) transfusion and transplantation

(iv) radiation chimeras

(2) Peri-zygotic chimerism

in man, they are included because it seems reasonable to expect that examples will be found in the future. Mosaics can be divided into two basic categories: those that are genetically uniform and those in which the mosaicism results from a genetic difference. This second category is chimerism.

\section{Genetically Uniform Mosaics}

Included in this class are all organisms with mosaic-like appearance which are not demonstrably due to genetic differences between the phenotypically or functionally different cells. Russell (1964), in her discussion of functional mosaicism in the mouse, includes in this category only examples of demonstrable functional differences in the cells, i.e. situations in which given genes are known to function in only some cells. To avoid exclusion of phenotypic variants indistinguishable from those of known origin, we prefer a more inclusive definition. Causative agents may be entirely extranuclear, extracellular, or even remote from the affected areas.

(I) Caused by Specific Genes-Pattern Loci. Early genetic investigation of mammalian coat colour revealed the existence of specific genes for mosaics or patterned coats, just as there were genes for coat colour itself. These can be inherited as simple Mendelian factors. The white forelock and heterochromia associated with the Waardenburg syndrome is the most striking example of this type of human mosaicism (Waardenburg, Franceschetti, and Klein, I96I). This condition is determined by an autosomal dominant gene with variable expressivity and incomplete penetrance, and there is no reason to doubt that the mutant gene is present in all cells of an affected individual. Other examples of this phenomenon in man would include the café au lait spots observed in neurofibromatosis and xeroderma pigmentosa (Waardenburg et al.,; 1961; Stern, I960). Russell (1964) has excluded 'spotting genes' from her discussion of functional mosaicism in the mouse on the grounds that they probably represent a process of histological differentiation.

(2) Caused by Variation in Gene Expression.

(a) LYON PRINCIPLE OF MAMMALIAN X CHROMOSOME INACTIVATION. In order to explain certain observations relating to the distribution of colour pattern in female mice heterozygous for two $\mathrm{X}$-linked mutants, Lyon (196r) proposed that early in embryonic development of the female mammal, one $\mathrm{X}$ chromosome in each cell becomes genetically inactive and that maternally and paternally derived $\mathrm{X}$ chromosomes are inactivated randomly. Each female thus becomes a mosaic for the expression of genes on the $\mathrm{X}$ chromosome and two distinct cell populations will exist in heterozygotes for X-linked genes. Lyon later presented observations on human X-linked conditions which appear to support her theory (1962, 1963). Several lines of evidence have tended to substantiate mosaicism for $\mathrm{X}$ chromosome activity in human females (Beutler, Yeh, and Fairbanks, 1962; Davidson, Nitowsky, and Childs, 1963), and the Lyon hypothesis that the normal human female is a mosaic of $\mathrm{X}$ chromosome activity can be considered as a general principle.

Since this phenomenon is a normal aspect of all 
human females it might be considered out of place in this classification. We include it because of its significance in the expression of X-linked mutants in the female and the understanding of certain fundamental aspects of embryogenesis in mammals as well as its relation to certain abnormal conditions which will be discussed.

(b) VARIEGATED-TYPE POSITION EFFECT. Muller (1930) in classifying X-ray induced changes in Drosophila melanogaster found an unexpected class which he called 'ever-sporting displacement'. This class was characterized by chromosomal rearrangements which resulted in a mottled phenotype. This mottled phenotype resulted only when a gene that was normally located in a euchromatic section of a chromosome became involved in a translocation and was placed next to heterochromatin. Variegation was attributed to and dependent on the abnormal proximity of the affected loci to a region of heterochromatin. That no permanent change in the affected loci occurred was shown by a return to normal activity when the locus was returned to its normal position (Kaufmann, I942). The extent of variegation could be influenced by environmental agents such as temperature and the presence of a different heterochromatin (Gowen and Gay, 1934). The influence of the heterochromatin was not restricted to immediately adjacent loci, but showed a spreading effect along the transposed segment. This phenomenon recently has been observed in mice (Russell and Bangham, 196I; Cattanach, 1963) in which a coat colour gene normally on an autosome was translocated to the $\mathrm{X}$ chromosome, resulting in a mosaic coat colour in females. The similarity in phenotype occurring from a translocation to heterochromatin and to the $\mathrm{X}$ chromosome suggested some relation between the mechanisms involved in the normal $\mathrm{X}$ chromosome inactivation and the heterochromatic influence on genes placed abnormally close to heterochromatin.

(c) Controlling elEMENTs. Variegations of both leaf and flower colour in plants have been selected for novelty value and are now a familiar observation. A similar phenomenon in corn in which the kernels have normally pigmented areas alternating with unpigmented areas has been extensively investigated genetically. Variegation is associated with the activity of a specific colour gene and colour variegation seems to be due to an instability of this locus. Rhodes (194I) demonstrated that the mutability was associated with the presence of a specific genetic element other than that of the colour locus and such an element was termed a controlling element. McClintock (1950, 1956) and Brink (1964a) have demonstrated that these mutable loci are under the influence of nuclear elements which seem to be similar to the heterochromatin of Drosophila. Both workers have drawn attention to the similarity of the phenomena and have suggested a similar underlying mechanism. McClintock (196I) has drawn a parallel between controlling elements in corn and those in bacteria and bacteriophage where precise mechanisms for control of gene activity are known to exist. Brink (1964b) has specifically indicated the relation of differentialpyknosis and gene control and has suggested aw similarity of mechanism involving controlling? elements in corn, variegated type position effectso in Drosophila and mice, and in the inactivation of the female mammalian $\mathrm{X}$ chromosome.

(3) Non-genetic Inheritance-Extranuclearo Structures. The significance of non-genetic or extranuclear structures as a cause of human cellularmosaicism has yet to be demonstrated. The possibility that extranuclear structures can contri bute to tissue mosaicism is well established in plants where chloroplast variation is a known source of mosaicism (Cramer, 1954; Neilson-Jones, 1937). The existence of self-replicating structureso in the cytoplasm (Catcheside, 1958) and the sug-o gestion that extranuclear structures may be an important influence on subsequent structure (Mar kert, 1964; Stern, 1957) increase the likelihood of the hypothesis that accidents or changes in non-nuclear structures may lead to subsequento mosaicism.

\section{Chimeras}

The term 'chimera' is a borrowed descriptive term. The original chimera was a Greek mythologi cal being with a lion's head, a goat's body, and an serpent's tail. The term was first used in a bios logical context by Winkler (1907) to describe the plant he created by grafting together two differento species. Such an organism is composed of two distinctly different cell lines exactly like the species of their origin. Therefore a chimera is defined as and organism which is not genetically uniform throughout Although Winkler demonstrated that such variega tion could have its origin in the combination of two different individuals, it was soon recognized that not all variegation was attributed to different genotypes (genetically uniform mosaics) nor did alb genetic variegation necessarily originate in two different individuals.

The term 'chimera' has been used extensively in? botanical literature with reference to plant variega- 0 tion resulting from genotypic differences aso distinguished from variegation due to non-genetic 
factors such as chloroplasts or viruses or to genetically uniform mosaics. It was used in the zoological field to describe the erythrocyte mosaicism in cattle observed by Owen in 1945. Cytogenetic and cytochemical techniques are currently revealing the existence and complexity of chimerism in man. At times the term has been used in its fullest sense to include all genetic mosaics, but there has been some suggestion that the term should be restricted to those genetic mosaics in which the mosaicism involves an entire genome, and exclude those mosaics in which alternations of a basic genome give rise to a second or further cell lines (Russell, 1964; Chu, Thuline, and Norby, 1964). We consider it preferable to include these.

Chimerism may be the result of an event occurring at any point during the life of the individual (post-zygotic) or it may be the result of an event before or at the time of fertilization and the formation of the zygote (peri-zygotic). Postzygotic chimerism may involve a single zygote and result from an event in a single genome, which gives rise to one or two new genotypes which are mutational alterations of the original genotype. It may also involve cells derived from different zygotes by some accidental or artificial transfer of tissue from one individual to another. Currently, a great deal of attention is being given to the possibility of one or more genomes being involved through participation of more than two germ cells at the time of fertilization (peri-zygotic) and the different mechanisms which may be involved (Lancet, 1965).

\section{Post-zygotic Chimerism.}

(a) INVOLVING CELLS FROM A SINGLE ZYGOTE. Although all mosaics included in this category are in general the result of a mutational event, four known mechanisms will be discussed. In all four, the extent and nature of the mosaicism depend on the time of the event and the type of cells deriving from it. The detection of this form of mosaicism may depend on whether or not germ tissue is involved.

(i) Somatic crossing-over. Of the four suggested mechanisms, only somatic crossing-over has not been demonstrated in man, though its existence as a cause of mosaicism has been recognized since Stern's classic genetic demonstration in Drosophila (1936). Basically, it is an exchange between homologous chromosomes at mitosis (rather than meiosis). If it involves a heterozygous locus, it will result in two new genotypes, each homozygous for one allele. Although early opinion attributed exchange between mitotic chromosomes to the intimate mitotic pairing observed in Diptera, genetic evidence of mitotic recombination has been demonstrated in other organisms (Pontecorvo and Käfer, I958). Conclusive evidence for somatic crossing-over in man has not been demonstrated. However, both cytological and genetic observations have prompted its suggestion as a possibility. German (1964) has observed association of homologous chromosomes from human blood cell cultures in a configuration which suggests chromatid interchange. As yet, no proof of this interchange is available, nor has it been demonstrated in vivo. Goudie (1957) has suggested somatic crossing-over to explain the apparently homozygous red blood cells occasionally encountered in low percentages in heterozygous individuals.

(ii) Somatic mutation. All replication of somatic material is subject to errors and mutational changes, whether of mitotic or meiotic origin. If a meiotic chromosome or gene is involved, the resulting individual is a mutant or is heterozygous for a mutation. If chromosomes subsequent to fertilization are involved, only part of the organism will be affected and the individual will be a mosaic. The demonstrated frequency of spontaneous mutation makes it seem likely that all human beings are to some extent mosaics. Such mutational events have been suggested as the probable origin of demonstrated mosaicism, particularly involving pigmentation (i.e. heterochromia, spotting). Davis and Shaw (I964) reported a human mosaic for skin pigmentation involving large areas of the body and have suggested an early somatic mutation as its origin. Blood cell mosaicism has been explained by somatic mutation (Atwood and Scheinberg, 1958; Atwood and Pepper, 196I). Neoplasms should perhaps be excluded from this group on the basis that they do not involve areas of uniform differentiation.

(iii) Somatic segregation and reduction. We have included somatic segregation as a separate entity, though it is really a specific somatic mutational event. It involves a mitotic segregational disturbance resulting in an abnormal chromosome distribution. Its significance in human disorders is currently being demonstrated cytologically in cases in which certain individuals who seem to have only a 'partial' syndrome are found to be cytological mosaics, and the disorder is due to a genetic imbalance in some of the cells. The widely accepted mechanism for chromosome mosaicism is nondisjunction or a failure of two chromatids to move to opposite poles at mitotic anaphase resulting in two new cell lines $(2 n+I$, and $2 n-I)$ as well as an original $2 n$ cell line (except at the first cleavage division). According to Wilson (1928), nondisjunction was first described in Oenothera and 
Datura by Gates in 1908 and has subsequently been widely demonstrated in both plants and animals, though the severity of its effect is much less in plants. It is now thought to be a frequent cause of problems in sex differentiation resulting in pseudohermaphrodism, sexual ambiguity, and intersexuality (Ford, 1960; Ferrier, Shepard, Gartler, and Burt, 196I ; Greenblatt, Dominguez, Mahesh, and Demos, I964; Ross, Holland, Kiser, and Douglas, 1965). Although mitotic pairing of homologous chromosomes normally occurs in many species of Diptera it is rare in other organisms. However, chromosome arrangements suggestive of somatic pairing have been sporadically reported and somatic reduction resulting from meiotic-like segregation of paired chromosomes observed in both treated and untreated plant material (Huskins, 1948) indicates another possible mechanism for somatic segregation. Cells produced by such a division would be hemizygous or homozygous for all genes.

(iv) Polyploidy. A number of recent reports have stressed observations of endoreduplicated chromosomes in cultured cells from patients with normal chromosome complements (Aspillaga, $\mathrm{Neu}$, and Gardner, 1964; Bishun and Morton, 1965). Polyploidy, or duplication of complete haploid sets of chromosomes, is a rather common deviation from diploidy (Wilson, 1928). It is usually observed in old, highly specialized or degenerate cells. For a long time it was presumed that these cells probably arose by a replication of the chromosomes without cell division (endoreduplication). Although this process automatically immediately creates a chromosomal mosaicism, it appears to have little effect on variant gene expression. More recently, fusion of somatic cells has been suggested and it may not be a rare event (Ephrussi and Sorieul, 1962). Such somatic cell mating has been suggested as the possible origin of a 'hybrid' blood cell type in a bovine twin chimera (Stone, Friedman, and Fregin, 1964). Generalized mosaicism for cells of different ploidy will also be discussed below.

(b) INVOLVING CELLS DERIVED FROM DIFFERENT ZYGOTES.

(i) Chorionic vascular anastomosis. Chorionic vascular anastomoses are common in bovine twins, and were recognized as early as 1916 by Lillie as a cause of the freemartin condition of the female twin of an unlike sex pair. The classic demonstration that this type of anastomosis could give rise to mosaicism was made by Owen (1945), who was able to demonstrate two populations of serologically different red cells in such twins. He concluded that exchange between the twins must have included ancestral haemapoietic tissue, since two types of erythrocytes could be antigenically detected until $\stackrel{\overparen{\Phi}}{\rightarrow}$ adulthood. Placental fusions have been described $\vec{F}$ in mice (McLaren and Michie, 1959) and in man (Benirschke, 196I).

Vascular anastomoses are apparently rare in $\frac{O}{\bar{D}}$ human dizygotic twins, but blood group studies $\frac{\widehat{\sigma}}{\vec{\sigma}}$ indicate that they can occur. Dunsford, Bowley, $\stackrel{\varnothing}{\varnothing}$ Hutchison, Thompson, Sanger, and Race (1953) is documented the first case of red blood cell mosaicism $\vec{\circ}$ in twins. Since then several cases have been. described (Race and Sanger, 1962). The most $\vec{\omega}$ recent case, to our knowledge, is that described by Chown, Lewis, and Bowman (1963). Although vascular anastomosis in cattle results in a freemartin $\dot{\omega}$ condition, the fertility of human blood group $\omega$ chimeras does not appear to be diminished.

(ii) Maternal-foetal exchange. The regularity with which erythroblastosis occurs under predicted circumstances has long since destroyed the concept $\vec{c}$ that the placental barrier between mother and $\mathbb{D}$ foetus is complete. It has been further demonstrated $\frac{}{\mathbb{D}}$ that violation of the barrier is not restricted to $\rightrightarrows$ soluble substances. Bleeding of the foetus into the maternal circulation has been recognized as a cause $\overrightarrow{\vec{\theta}}$ of anaemia in the newborn (Chown, 1954; Wiener, 1948; Gunson, 1957; Kirkman and Riley, 1959). There is some evidence that the reverse exchange, $O$ maternal-foetal transfusion, can also occur, and it has been proposed as a cause of plethora (Michael and Mauer, I96r; Smith, Duhring, Greene, Rochlin, and Blakemore, 196I). In the first case, $\stackrel{\odot}{\perp}$ the mother, and in the second case the foetus, would $\overrightarrow{\vec{P}}$ be, at least temporarily, a blood cell chimera. There $\frac{}{3}$ is as yet no evidence as to whether a persisting? mosaicism is established in viable embryos by this mechanism. Recently, Taylor and Polani (1965) have reported an $\mathrm{XX} / \mathrm{XY}$ aborted foetus in which they suggest the chimerism may have resulted from: colonization in the embryo of maternal cells $\underset{3}{\exists}$. through breakdown of the placental barrier.

(iii) Transfusions and transplantations. Winkler's original chimera resulted from successfully unitingo parts of two different plants. In the resulting plant, $>$ cells descended from each of the ancestral plantso maintained their integrity, a fact that can be demonstrated by asexual propagation. A similaro human chimera is created, for a short time, when N blood of one individual is transfused into another. N Such transfusion is successful only if certain geneti- $\omega$ cally determined characters are the same or compatible. A much closer parallel to plant grafting isc found in tissue transplants in which apparentlyes animals are much more able to 'recognize' and reject foreign tissue. Although tissue transplanta-o tion is still at an undeveloped and primitive stage in 
human beings, it is a routine and extremely useful procedure in certain areas of mouse genetics (Snell, 1958).

(iv) Radiation chimeras. An exception to the isogenicity required for successful tissue transplant is found following post-irradiation injection of bone-marrow. Since Jacobson, Simmons, Marks, Gaston, Robson, and Eldredge (I95I) and Lorenz, Uphoff, Reid, and Shelton (I95I) discovered that mice recovered from an expected lethal dose of $\mathrm{X}$ rays if irradiation was followed by injection of bone-marrow from non-irradiated individuals, this has been the object of extensive investigation both from the immunological and radiation treatment viewpoints (Congdon, 1962). Implantation and persistence of grafted cells from genetically distinct donors have been demonstrated immunologically (Lindsley, Odell, and Tausche, I955), cytologically (Ford, Hamerton, Barnes, and Loutit, 1956), and by a number of other means (Congdon, 1962), and apparent permanent chimerism is established in marrow, lymphatic, and blood cells.

Peri-zygotic Chimerism. Goldschmidt and Katsuki (1927) determined that in Bombyx mori, the silkworm, gynandromorphism was an inherited condition resulting from the action of a single gene which produced somatic mosaics through the retention of one polar body nucleus. That is, the eggs had two nuclei and fertilization of both nuclei by different sperm followed by fusion of the two into a single developing mass produced mosaics for sexual or somatic characteristics or both, depending upon the nature of the sperm participating in the fertilization. In 1957 Beatty suggested chromosome mosaicism as an alternative to mutation to explain mammalian colour and sex mosaicism. Three possible peri-zygotic mechanisms were suggested: (I) fertilization of a double secondary oocyte; (2) fertilization of a double matured oocyte; and (3) polynuclear ovarian eggs. The first mechanism is identical with the 'immediate cleavage', as observed by Braden (1957) in the mouse. This process involves the production of two almost equally sized cells from the first meiotic division, both of which may participate in embryo formation. One, neither, or both may extrude a second polar body, and one, neither, or both may be fertilized. This process can result in various forms of chimerism, $1 n / 2 n, 2 n / 2 n$, $2 n / 3 n$, depending upon the nature of the fertilization process. The diploid-triploid mosaics described by Böök and Santesson (1960, 196r) and Ferrier, Ferrier, Stalder, Bühler, Bamatter, and Klein (1964) are probably examples of this type of mosaicism.
In the recent medical literature, several cases of true hermaphrodism in humans have been reported in which the condition is attributed to $\mathrm{XX} / \mathrm{XY}$ chromosome mosaicism (see Bain and Scott, 1965, for review). The possibility that such mosaicism has arisen through a series of mitotic events during early cleavage has been ruled out in most cases by red blood cell antigen mosaicism which indicates that more than two germ cells must have participated in the fertilization process. Since such individuals are mosaics of normal yet cytologically and genetically distinct cells, it seems likely that more than two germ cells have participated in fertilization and in such a manner that the cytological equivalent of two complete zygotes is involved (termed geminism by B. Chown, 1965, personal communication). Several mechanisms have been described to account for these mosaic hermaphrodites. Several other mechanisms for hermaphrodite production through mosaicism in other organisms have been described in cytogenetic papers. Suggested mechanisms include dispermic fertilization of the ovum plus a second meiotic product and fusion of two simultaneous and independently fertilized ova. The latter has been artificially achieved in mice (Mintz, 1964).

\section{Summary}

The term 'mosaicism' is now used extensively in human cytogenetics. In fact, the term has had long usage and specific meanings in human genetics. A proposed classification is presented.

We should like to express our appreciation to Professor F. C. Fraser and Dr. B. B. Mukherjee and their students for a critical reading of the manuscript.

\section{REFERENCES}

Aspillaga, M. J., Neu, R. L., and Gardner, L. I. (1964). Chromosomal endoreduplication in a case of testicular feminisation. Lancet, $\mathbf{r}, 937$.

Atwood, K. C., and Pepper, F. J. (196r). Erythrocyte automosaicism in some persons of known genotype. Science, 134, 2100.

- and Scheinberg, S. L. (1958). Somatic variation in human erythrocyte antigens. f. cell. comp. Physiol., 52, Suppl. 1, 97.

Bain, A. D., and Scott, J. S. (1965). Mixed gonadal dysgenesis with $\mathrm{XX} / \mathrm{XY}$ mosaicism. Lancet, 1 , 1035 .

Beatty, R. A. (1957). Parthenogenesis and Polyploidy in Mammalian Development. Cambridge University Press, London.

Benirschke, K. (196I). Accurate recording of twin placentation. Obstet. and Gynec., 18, 334.

Beutler, E., Yeh, M., and Fairbanks, V. F. (1962). The normal human female as a mosaic of $\mathrm{X}$ chromosome activity. Proc. nat. Acad. Sci. (Wash.), 48, 9.

Bishun, N. P., and Morton, W. R. M. (1965). Endoreduplicated chromosomes. Lancet, $1,1169$.

Böök, J. A., and Santesson, B. (1960). Malformation syndrome in man associated with triploidy (69 chromosomes). ibid., 1,858 . - , and - (196I). Nuclear sex in triploid XXY human cells. ibid., 2, 318.

Braden, A. W. H. (1957). Variation between strains in the incidence of various abnormalities of egg maturation and fertilization in the mouse. F. Genet., 55, 476. 
Brink, R. A. (1964a). Genetic repression of $R$ action in maize. In The Role of Chromosomes in Development, ed. M. Locke, p. I83. Academic Press, New York.

(1964b). Genetic repression in multicellular organisms. Amer. Nat., 98, 193.

Catcheside, D. G. (1958). A discussion on the cytoplasm in variation and development. Proc. roy. Soc. B, 148, 285.

Cattanach, B. M. (I963). The inactive-X hypothesis and position effects in the mouse. (Abstract.) Genetics, 48, 884 .

Chown, B. (1954). Anaemia from bleeding of the fetus into the mother's circulation. Lancet, I, I2I5.

- Lewis, M., and Bowman, J. M. (1963). A pair of newborn human blood chimeric twins. Transfusion (Philad.), 3, 494.

Chu, E. H. Y., Thuline, H. C., and Norby, D. E. (I964). Triploiddiploid chimerism in a male tortoiseshell cat. Cytogenetics, 3, 1 . Congdon, C. C. (1962). Radiation injury: bone marrow transplantation. Ann. Rev. Med., 13, 203.

Cramer, P. J. S. (1954). Chimeras. Bibliogr. genet., 16, 193.

Davidson, R. G., Nitowsky, H. M., and Childs, B. (I963). Demonstration of two populations of cells in the human female heterozygous for glucose-6-phosphate dehydrogenase variants. Proc. nat. Acad. Sci. (Wash.), 50, $48 \mathrm{r}$.

Davis, D. G., and Shaw, M. W. (1964). An unusual human mosaic for skin pigmentation. New Engl. F. Med., 270, 1384.

Dunsford, I., Bowley, C. C., Hutchison, M., Thompson, J. S., Sanger, R., and Race, R. R. (1953). A human blood-group chimera. Brit. med. $\boldsymbol{F}$., 2, $8 \mathrm{I}$.

Engel, E. (1965). Mosaicism. New Engl. F. Med., 272, 34.

Ephrussi, B., and Sorieul, S. (1962). Mating of somatic cells in vitro. Univ. Mich. med. Bull., 28, 347.

Ferrier, P., Ferrier, S., Stalder, G., Bühler, E., Bamatter, F., and Klein, D. (1964). Congenital asymmetry associated with diploidtriploid mosaicism and large satellites. Lancet, $\mathbf{I}, 80$.

-, Shepard, Th., Gartler, S., and Burt, B. (I96I). Chromatinpositive gonadal dysgenesis and mosaicism. ibid., I, I I 70 .

Ford, C. E. (1960). Human cytogenetics: its present place and future possibilities. Amer. F. hum. Genet., 12, 104

-, Hamerton, J. L., Barnes, D. W. H., and Loutit, J. F. (1956). Cytological identification of radiation-chimaeras. Nature (Lond.), $\mathbf{1 7 7}, 452$.

German, J. (1964). Cytological evidence for crossing-over in vitro in human lymphoid cells. Science, 144, 298.

Goldschmidt, R., and Katsuki, K. (1927). Erblicher Gyandromorphismus und somatische Mosaikbildung bei Bombyx mori L. Biol. $Z$ bl., 47, 45 .

Goudie, R. B. (I957). Somatic segregation of "inagglutinable" erythrocytes. Lancet, $\mathbf{I}, 1333$.

Gowen, J. W., and Gay, E. H. (1934). Chromosome constitution and behaviour in eversporting and mottling in Drosophila melanogaster. Genetics, 19, 189.

Greenblatt, R. B., Dominguez, H., Mahesh, V. B., and Demos, R. (1964). Gonadal dysgenesis intersex with $\mathrm{XO} / \mathrm{XY}$ mosaicism. 7. Amer, med. Ass., 188, 22 I.

Gunson, H. H. (1957). Neonatal anaemia due to foetal haemorrhage into the maternal circulation. Pediatrics, 20, 3.

Hannah-Alava, A. (1960). Genetic mosaics. Scient. Amer., 202, I 19.

Huskins, C. L. (1948). Segregation and reduction in somatic tissues: I. Initial observations in Allium cepa. F. Hered., 39, 31 I.

Jacobson, L. O., Simmons, E. L., Marks, E. K., Gaston, E. O., Robson, M. J., and Eldredge, J. H. (I95I). Further studies on recovery from radiation injury. F. Lab. clin. Med., 37, 683.

Kaufmann, B. P. (1942). Reversion from roughest to wild type in Drosophila melanogaster. Genetics, 27, 537.

Kirkman, H. N., and Riley, H. D., Jr. (1959). Posthaemorrhagic anaemia and shock in the newborn: a review. Pediatrics, 24, 97. Lancet (1965). Chimaeras and mosaics. I, ro52.

Lillie, F. R. (1916). The theory of the freemartin. Science, 43, 6Ir

Lindsley, D. L., Odell, T. T., Jr., and Tausche, F. G. (1955) Implantation of functional erythropoietic elements following total-body irradiation. Proc. Soc. exp. Biol. (N.Y.), 90, 512.

Lorenz, E., Uphoff, D., Reid, T. R., and Shelton, E. (I95I). Modification of irradiation injury in mice and guinea pigs by bone-marrow injections. F. nat. Cancer Inst., 12, 197.

Lyon, M. F. (196I). Gene action in the X-chromosome of the mouse
(Mus musculus L.). Nature (Lond.), 190, 372

(1962). Sex chromatin and gene action in the mammalian X-chromosome. Amer. F. hum. Genet., 14, 135.

- (1963). Attempts to test the inactive-X theory of dosage compensation in mammals. Genet. Res., 4, 93.

McClintock, B. (1950). The origin and behavior of mutable loci $\frac{\overline{0}}{\overline{0}}$ in maize. Proc. nat. Acad. Sci. (Wash.), 36, 344.

(I956). Controlling elements and the gene. Cold Spr. Harb. Symp. quant. Biol., 21 , 197.

(I96I). Some parallels between gene control systems in maize and bacteria. Amer. Nat., 95, 265.

McLaren, A., and Michie, D. (1959). Experimental studies in $\overrightarrow{0}$ placental fusion in mice. $\mathcal{F}$. exp. Zool., 141, 47.

Markert, C. L. (I964). The role of chromosomes in development. In The Role of Chromosomes in Development, ed. M. Locke, p. I. $\boldsymbol{\omega}$ Academic Press, New York.

Michael, A. F., Jr., and Mauer, A. M. (I96I). Maternal-foetal transfusion as a cause of plethora in the neonatal period. Pediatrics, 28, 458 .

Mintz, B. (1964). Formation of genetically mosaic mouse embryos $\omega$ and early development of "lethal $\left(\mathrm{t}^{12} / \mathrm{t}^{12}\right)$-normal" mosaics. 7. exp. Zool., 157, 273.

Muller, H. J. (1930). Types of visible variation induced by X-rays in Drosophila. F. Genet., 22, 299.

Neilson-Jones, W. (1937). Chimeras: a summary and some special aspects. Bot. Rev., 3, 546.

Owen, R. D. (1945). Immunogenetic consequences of vascular $(S$ anastomoses between bovine twins. Science, 102, 400.

Pontecorvo, G., and Käfer, E. (1958). Genetic analysis based on $\underset{\mathbb{D}}{\vec{D}}$ mitotic recombination. Advanc. Genet., 9, $7 \mathrm{I}$.

Race, R. R., and Sanger, R. (1962). Blood Groups in Man, 4th ed., p. 375. Blackwell, Oxford.

Rhodes, M. M. (194I). The genetic control of mutability in maize. Cold Spr. Harb. Symp. quant. Biol., 9, 138.

Robinson, G. C., Dikrainian, D. A., and Roseborough, G. F. (1965). ஓ Congenital Horner's syndrome and heterochromia iridum. Pediatrics, 35, 103.

Ross, G. T., Holland, J. M., Kiser, W. S., and Douglas, G. W. (I965). XO/XY chromosomal mosaicism and extragenital stigmata of Turner's syndrome in a phenotypic male. $\mathcal{F}$. clin. Endocr., 25, I4I.

Russell, L. B. (1964). Genetic and functional mosaicism in the mouse. In The Role of Chromosomes in Development, ed. M. Locke, \& p. I 53. Academic Press, New York.

, and Bangham, J. W. (I96I). Variegated-type position effects in the mouse. Genetics, 46, 509.

Smith, K., Duhring, J. L., Greene, J. W., Jr., Rochlin, D. B., and Blakemore, W. S. (I96I). Transfer of maternal erythrocytes across the human placenta. Obstet. and Gynec., 18, 673.

Snell, G. D. (1958). Histocompatibility genes of the mouse. II. Production and analysis of isogenic resistant lines. 7 . nat. Cancer Inst., 21, 843.

Stern, C. (1936). Somatic crossing over and segregation in Drosophila melanogaster. Genetics, $21,625$.

- (1957). Perspectives in chromosome physiology. Proc. genet. Soc. Can., 2, 3.

(1960). Principles of Human Genetics, 2nd ed. W. H. Freeman Co., San Francisco.

Stone, W. H., Friedman, J., and Fregin, A. (I964). Possible somatic 음 cell mating in twin cattle with erythrocyte mosaicism. Proc. nat. Acad. Sci. (Wash.), 51, 1036.

Taylor, A. I., and Polani, P. E. (1965). XX/XY mosaicism in man. 을 Lancet, I, 1226.

Waardenburg, P. J., Franceschetti, A., and Klein, D. (I96I). O Genetics and Ophthalmology. Koninklijke van Gorcum, The Netherlands.

Wiener, A. S. (1948). Diagnosis and treatment of anaemia of the $N$ newborn caused by occult placental hemorrhage. Amer. $\mathcal{F}$. Obstet. $\omega$ Gynec., 56, 717 .

Wilson, E. B. (1928). The Cell in Development and Heredity, 3rd ed. Macmillan, New York.

Winkler, H. (1907). Uber Pfropfbastarde and pflanzliche $\frac{C}{(\mathbb{2}}$ Chimaeren. Ber. dtsch. bot. Ges., 25, 568. 